\title{
Review
}

\section{How-to establish PCST. Two handbooks on science communication}

\author{
Alessandro Delfanti

\begin{abstract}
M. Bucchi and B. Trench (eds.), Handbook of Public Communication of Science and Technology, Routledge (2008).

D. Cheng, M. Claessens, T. Gascoigne, J. Metcalfe, B. Schiele and S. Shi (eds.), Communicating

Science in Social Contexts: New models, new practices, Springer (2008).
\end{abstract}

\begin{abstract}
In 2008 two collections were published: the Handbook of Public Communication of Science and Technology, edited by Massimiano Bucchi and Brian Trench, and Communicating Science in Social Contexts: New models, new practices, edited by Donghong Cheng and five other scholars from China, Canada, Belgium and Australia. These books try to define and draw the boundaries of science communication's field from both a theoretical and empirical point of view. But do we need to establish it as a distinct research field? For a number of decades, a growing community of scholars and communicators is trying to reply positively to this question, but the need to look outside the disciplinary boundaries, to other academic fields, is still vital.
\end{abstract}

Handbooks are one of the means to establish and strengthen a discipline, drawing its boundaries within the cultural and academic world. In 2008 we have witnessed the publication of two collective volumes dedicated to Public Communication of Science and Technology, an emergent field positioned in between the older and more well- established sectors of Science and Technology Studies and Media Studies: the Handbook of Public Communication of Science and Technology, edited by Massimiano Bucchi and Brain Trench, ${ }^{1}$ and of Communicating Science in Social Contexts: New models, new practices, edited by Donghong Cheng and five other scholars from China, Canada, Belgium and Australia. ${ }^{2}$ Both books bring together contributions from an international panel of scholars and are focused on theoretical issues, communication practices as well as policy issues. Although they suffer from the heterogeneity one can expect from projects as broad and multidisciplinary as these, they promise to be helpful for those scholars who work in the PCST field and want to follow what is state-of-the-art and address some of the core issues of today's research.

The books share several characteristics, such as the willingness to take both a theoretical analysis on science communication's models and a broad view on communicative practices and practitioners. We could see this multiple focus also from the point of view of the three categories Massimiano Bucchi and Brian Trench propose in the introductive chapter of the Handbook of Public Communication of Science and Technology: actors, arenas and issues. Who is involved in science communication, in what spaces does the communication flow and what challenges and controversies are at stake in those processes? Finally, both books try to demonstrate that several science communication models coexist in contemporary societies, call them as you prefer: linear, dialogical, top-down, participatory, deficit model. This theoretical point is one of the best tools given by these books to scholars who want to critically approach this field: the need to wonder "under what conditions do different forms of public communication of science emerge".

However, it is also noteworthy that these volumes have been published only some months for one and other, they share several chapters' authors (and themes) and, especially, they have a common birthplace: the PCST network ${ }^{3}$ and its activities devoted to the establishment, the stabilising and the visibility of a worldwide scholars' and institutions' network working on public communication of science and technology. In fact, we choose to review them together because the publication of these books is part of 
an explicit effort to establish PCST as an independent academic field, different from both science and technology studies and communication and media theory. As Brian Trench writes, "science communication has been telling a story of its own development, repeatedly and almost uniformly": the birth and death of the public understanding of science movement in Great Britain, the foundation of the first academic journals dedicated to PCST research, the rise of the participatory and dialogic models against the deficit one. In explaining the birth of the science communication as a research field, Bucchi points to the attention given to it by sociologists of science. They were "the more sophisticated victims of the traditional conception" of science communication: being seen as totally detached from science, it was considered of scarce importance. Now there is widespread awareness that the public arena is one of the places where scientific knowledge is produced, debated, shared and submitted to the control of both scientific community and society in a broader sense.

Nonetheless, apart from this foundational myth of PCST, we should wonder whether we need the creation of a new discipline such as public communication of science. For Donghong Cheng and the other editors of Communicating Science in Social Contexts, science communication already "is a distinct research field"; well, this review is published in the Journal of Science Communication; every two years the PCST conferences bring together hundreds of scholars from all over the world. We are part of an international researcher and practitioner community. However, the partially successful drive to build this community does not exempt it from comparing itself against the outside. PCST research has moved forward, as the growing quality and broadness of these books testify, but still chases its major cousins. At one side Science and Technology Studies, with its emphasis on power structures, historical dimension and the blurring of boundaries between society and science (do they exists as separate entities?). At the other one, media and communication studies, a research sector which has already replied to several questions we are still posing in the PCST research. Just to draw on a couple of examples, we can address two themes just touched on by the books we are reviewing - and by public communication of science research as a whole - but by now well established and studied in those two disciplines: the theoretical emphasis posed by STS on co-production between science and society, and the role in opening new spaces of deliberation and drawing a new kind of citizenship attributed by several media studies to the Internet. PCST scholarship should give more attention to what is outside its windows instead of stating its autonomy.

\section{Notes and references}

\footnotetext{
${ }^{1}$ M. Bucchi and B. Trench (eds.), Handbook of Public Communication of Science and Technology, Routledge (2008).

${ }^{2}$ D. Cheng, M. Claessens, T. Gascoigne, J. Metcalfe, B. Schiele and S. Shi (eds.), Communicating Science in Social Contexts: New models, new practices, Springer (2008).

3 "The International Network on Public Communication of Science and Technology (PCST) is a network of individuals from around the world who are active in producing and studying PCST", quotation from the PCST-10 Conference website, http://www.vr.se/pcst, accessed 22 November 2008.
}

How TO CITE: A. Delfanti, How-to establish PCST. Two handbooks on science communication, Jcom 07(04) (2008) R01 